\title{
TINGKAT KONSENTRASI ATLET KOTA LUBUKLINGGAU
}

\author{
Adika Fatahilah $^{1}$, Rais Firlando ${ }^{2}$ \\ STKIP PGRI Lubuklinggau \\ adika@stkippgri-lubuklinggau.ac.id
}

\begin{abstract}
ABSTRAK
Pentingnya memahami konsentrasi atlet dalam berolahraga bertujuan untuk membuat prediksi kemungkinan penampilan atlet menghadapi situasi tertentu dalam pertandingan maupun latihan, dan untuk mencari bibit-bibit atlet berbakat dalam cabang olahraga tertentu untuk meraih prestasi maksimal. Penelitian ini penelitian kualitatif dengan menggunakan metode deskriptif analisi. Sampel atlet kota Lubuklinggau teknik pengambilan sampel menggunakan puposive sampling sehingga mendapatkan 15 sampel dari lima cabang olahraga berbeda. Adapun hasil penelitian 15 orang sampel, 0 orang yang melewati kategori $10>$ persentase $(0 \%)$ yang tergolong kategori tinggi, 1 orang yang melewati kategori 9-10 persentase (7\%) tergolong kategori agak tinggi, 8 orang yang melewati kategori 7-8 persentase (53\%) tergolong kategori agak rendah, 6 orang yang melewati kategori 5-6 persentase (40\%) tergolong kategori rendah. Rata-rata tingkat konsentrasi atlet belum ada yang mencapai kategori tinggi, maka dibutuhkan sebuah model latihan untuk meningkatkan konsentrasi atlet.
\end{abstract}

\section{Kata Kunci : konsentrasi, atlet kota Lubuklinggau}

\begin{abstract}
The importance of discussing athletes in matches that aims to make interesting predictions about athletes matches and training, and look for talented athletes in certain sports to obtain maximum performance. This research is a qualitative research using descriptive analysis method. The sample of Lubuklinggau city athlete sampling technique used puposive sampling to obtain 15 samples from five different sports. While the results of the study were 15 samples, 0 people who passed the category 10> percentage (0\%) belonging to the high category, 1 person who passed the category 9-10 percentages (7\%) belong to the rather high category, 8 people who passed the 7-8 category the percentage (53\%) belongs to the rather low category, 6 people who passed the 5-6 category (40\%) belongs to the low category. There is no average level concentration of athletes in the high category, so training models are needed to increase athlete concentration.
\end{abstract}

Keywords: concentration, Lubuklinggau city athletes

Dipublikasikan Oleh :

UPT Publikasi dan Pengelolaan Jurnal

Universitas Islam Kalimantan Muhammad Arsyad Al-Banjari Banjarmasin 


\section{PENDAHULUAN}

Setiap atlet harus memiliki struktur mental yang baik untuk mendukung pencapaian prestasinya. Peranan pelatih sagantlah penting dalam perencanaan, baik dari segi perogram latihan maupun kedaan psikologi atlitnya, dengan memberikan bimbingan kepada atlit agar siap secara fisik maupun mental saat sebelum dan sesudah pertandingan (Komarudin, 2015:48). Menurut Sumantra (2010:1) yoga secara inti adalah praktek mengolah raga, mengolah rasa, dan mengolah jiwa. Gunarsa (2008:89), "konsentrasi merupakan kemampuan yang sangat penting agar perhatian menjadi terpusat terhadap permainan dengan berbagai lika-likunya, serta terhadap taktik atau strategi untuk bermain sebaik-baiknya". Eugene F. Gauron dalam Mylsiyadu (2013:39), konsentrasi adalah suatu aktivitas pemusatan perhatian tertentu, dan mengemukkan ciri-ciri konsentrasi sebagai berikut: 1). Tertuju pada suatu benda pada suatu saat. 2). Merupakan keseluruhan. 3). Perhatian selektif terhadap pemikiran tertentu dan tidak ada perhatian terhadap objek atau pemikiran lain. 4). Menenagkan dan memperkuat mental.

Cox dalam Komarudin (2015:133), mengungkapkan konsentrasi merupakan kemampuan atlet untuk memusatkan perhatian pada informasi yang relevan selama kompetisi. Pendapat tersebut sejalan dengan Dalloway yang menyatakan bahwa konsentrasi diperlukan untuk meraih prestasi optimal, tidak hanya pada cabang olahraga yang beregu. Konsentrasi dipengaruhi oleh beberapa faktor antara lain usia, jenis kelamin, pengalaman, dan pengetahuan. Faktor usia mempengaruhi kemampuan konsentrasi karena kemampuan berkonsentrasi ikut berkembang sesuai dengan usia individu. Sugara (2013:108), “ pada dasarnya, konsentrasi yang pernah akan mampu kita dapatkan jika fokus pada suatu perhatian. Hanya saja ketika kita memiliki banyak masalah, pikiran kita menjadi terbagi dan yang paling parah biasanya kita memfokuskan perhatian kita pada masalah itu". Satiadarma (2000:224), " konsentrasi merupakan aslek yang dimilki penting dalam olahraga tidak hanya pada saat pertandingan tetapi juga pada saat latihan". Schmid dan Paper dalam satidarma (2000:228), mengemukkan bahwa konsentrasi merupakan hal yang amat penting bagi seorang atlet dalam menampilkan kinerja olahraganya. Komponen utama konsentrasi adalah kemampuan untuk memusatkan perhatian pada suatu hal tertentu dan tidak terganggu oleh stimulus internal mapupun eksternal yang tidak relevan. Berdasarkan pendapat para ahli di atas, dapat disimpulkan bahwa konsentrasi adalah kemampuan atlet untuk tetap fokus pada tugas yang harus dikerjakannya merupakan langkah awal untuk menampilkan permainan dengan baik. Stimulus internal adalah gangguan sensoris maupun pikiran seperti perasaan lelah, cemas, dan sebagainya. Stimulus eksternal adalah gangguan dari luar diri seperti sorak-sorai penonton, ejekan penonton, alunan musik yang keras, kata-kata yang menyakitkan dari penonton atau pelatih, kesalahan keputusan wasit dan lain-lain.

\section{METODE}

Penelititian ini menggunakan penelitian deskriptif analisis. Penelitian menggambarkan fenomena-fenomena yang ada yang berlangsung pada saat ini atau saat lampau. Pendekatan deskriptif ini menggambarkan tingkat konsentrasi atlet kota lubuklinggau yang berasal dari lima cabang olahraga yang berbeda. Dengan menggabarkan kondisi yang sebenarnya (Sukmadinata, 2005).

Penelitian dilakukan dikota Lubuklinggau, dengan jumlah sampel 15 atlet, teknik pengembilan sampel menggunakan teknik purposive sampling.

\section{HASIL DAN PEMBAHASAN}

Tinggi rendahnya konsentrasi diukur dengan skala psikologi Tes konsenterasi (Mylsidayu 2014:120). yang terdiri dari 0-99 angka yang telah diacak dimana atlet harus menemukan sebanyak mungkin angka dikolom yang seudah ditentukan digunakan untuk melihat konsentrasi atlet dijelaskan pada tabel:

Dipublikasikan Oleh : 
Tabel 1. Tingkat konsentrasi atlet kota Lubuklinggau

\section{No. Kode Responden Skor Skala Konsentrasi}

\begin{tabular}{|c|c|c|}
\hline 1. & R-1 P & 6 \\
\hline 2. & R-2 P & 5 \\
\hline 3. & R-3 P & 8 \\
\hline 4. & $\mathrm{R}-4 \quad \mathrm{P}$ & 7 \\
\hline 5. & R-5 P & 8 \\
\hline 6. & R-6 P & 5 \\
\hline 7. & R-7 P & 5 \\
\hline 8. & $\mathrm{R}-8 \quad \mathrm{P}$ & 7 \\
\hline 9. & R-9 P & 6 \\
\hline 10. & R-10 P & 8 \\
\hline 11. & R-11 P & 6 \\
\hline 12. & R-12 P & 7 \\
\hline 13. & R-13 L & 7 \\
\hline 14. & R-14 L & 8 \\
\hline 15. & R-15 L & 9 \\
\hline
\end{tabular}

Dapat dilihat bahwa dari klasifikasi skor dari skala tingkat konsentrasi atlet kota Lubuklinggau pada setiap skor skala dapat dilihat dari nilai rentang skor tinggi rendahnya konsentrasi atlet dijelaskan pada tabel.

Tabel 2. Klasifikasi tingkat konsentrasi berdasarkan skor setiap skala

\begin{tabular}{lcrr}
\hline Kategori & Rentang & Jumlah & Persentase \\
\hline Tinggi & $10>$ & 0 & $0 \%$ \\
Agak Tinggi & $9-10$ & 1 & $7 \%$ \\
Agak Rendah & $7-8$ & 8 & $53 \%$ \\
Rendah & $5-6$ & 6 & $40 \%$ \\
\hline
\end{tabular}

Dari tabel di atas dari 15 orang sampel, 0 orang yang tergolong kategori 10> persentase $(0 \%)$ yang masuk kategori tinggi, 1 orang yang tergolong kategori 9-10 persentase (7\%) masuk kategori agak tinggi, 8 orang yang tergolong kategori 7-8 persentase $(53 \%)$ masuk kategori agak rendah, 6 orang yang tergolong kategori 5-6 persentase (40\%) masuk kategori rendah. Dengan ratarata tingkat konsentrasi atlet 6,8 dengan begitu tergolong rendah. Maka dari itu dibutuhkan suatu model latihan mental atlet sebagai rujukan untuk meningkatkan konsentrasi atlet.

Gangguan konsentrasi dapat menghambat penampilan kerja atlet, karenanya atlet harus mampu berkonsentrasi yang tidak diperoleh begitu saja melainkan harus melalui serangkai proses latihan (Satiadarma, 2000:233). Metode serta teknik :

1. Program ACT (Attention Control Training) dapat diterjemahkan sebagai latihan mengendalikan perhatian

2. Memperluas kesadaran

3. Mengendalikan faktor eksternal dan internal

Gouron dalam Purnama (2013:40), memberikan beberapa petunjuk sebagai berikut : 1). Jauhkan pikiran dari suatu yang pernah dilakukan ataupun pernah dialami. 2). Pusatkan perhatian pada suatu tempat. 3). Tunjukan pusat perhatian pada satu lokasi tersebut. 4). Kosongkan pikiran biar tetap kosong. 5). Pindahkan dari sasaran khusus ke pusat perhatian seperti gambar panorama kemudian ikut dihadirkan suatu gambar besar memberikan kemungkinan masukan tanpa menyeleksinya, berupaya memusatkan perhatian terhadap semua benda, berhentilah dan kemudian kembali konsentrasi. Nofy Ongko \& Miftakhul Jannah, 2016) Mind Control Training dapat memberi efek positif untuk peningkatan konsentrasi atlet, a Mind Control Training pada

Dipublikasikan Oleh :

UPT Publikasi dan Pengelolaan Jurnal

Universitas Islam Kalimantan Muhammad Arsyad Al-Banjari Banjarmasin 
penelitianya terbukti dapat meningkatkan konsentrasi atlet. Dapat menjadi rujukan salah satu refrensi model latihan mental training yang menggabungkan antara cue word, visualisasi, dan kinsethetic feedback yang disebut Mind Control Training. Mind merupakan kunci utama dalam sebuah pertandingan. Atlet dengan mind yang baik atau tenang, maka tubuh dapat lebih rilaks menampilkan kemampuan terbaik.

\section{PENUTUP}

Konsentrasi merupakan aspek mental yang amat penting bagi atlet dalam menampilkan kinerja olahraganya. Gangguan konsetrasi ada dua Stimulus eksternal yaitu stimulus yang berasal dari luar tubuh yang dapat menganggu konsentrasi tersebut. Misalnya, sorakan penonton, alunan musik keras, kata-kata menyakitkan dari penonton atau pelatih dan perilaku tidak sportif dari lawan. Stimulus dari eksternal, seperti perasaan terganggu pada tubuh dan perasaan-perasaan lain yang menanggu fisik dan psikis seperti " saya benar-benar lelah" atau "jangan nervous", terlalu cemas, terlalu bergairah saat bertanding. Faktor makanan yang menganggu pencernaan. Dalam olahraga, masalah yang paling sering timbul akibat terganggunya konsentrasi adalah berkurangnya akurasi lemparan, pukulan, tendangan dan tembakan sehingga tidak mengenai sasaran. Akibat lebih lanjut jika akurasi berkurang adalah strategi yang sudah dipersiapkan menjadi tidak jalan, sehingga atlet akhirnya kebingungan, tidak tahu harus bermain bagaimana dan pasti kepercayaan dirinya pun akan berkurang. Unutuk menghindari keadaan tersebut, perlu dilakukan latihan berkonsentrasi.

\section{Kesimpulan}

Dari hasil survei pengukuran aspek konsentrasi atlet kota Lubuklinggau dengan sampel yang berasal dari lima cabang olahraga yang berbeeda diperoleh nilai degan rata-rata tingkat konsentrasi atlet 6,8 dengan melihat hasil tersebut aspek mental konsentrasi atlet masih tergolong kategori rendah. Mengingat aspek konsentrasi merupakan aspek sangat dibutuhkan yang harus dimiliki atlet dalam olahraga pada saat latihan dan saat pertandingan agar dapat menjadi perhatian lebih bagi para pelatih dan penggiat olahraga untuk melatih aspek psikis mental khususnya konsentrasi atlet.

\section{Saran}

Untuk para peneliti selanjutnya dapat disarankan untuk dapat mengembangkan atau merancang suatu model latihan mental atlet sebagai rujukan untuk memebuat program latihan yang berkualitas khususnya sebagai upaya meningkatkan konsentrasi atlet untuk mendapatkan top performa saat bertanding.

\section{REFERENSI}

Gunarsa, S. D. 2008. Psikologi Olahraga Prestasi. Jakarta: PT BPK Gunung Mulia.

Idrusputra. 2016. The Miracle of Hypnotic Persuasion Rahasia Mempengaruhi \& Mengendalikan Pikiran Orang Lain. Yogyakarta: Media Pressindo

Jannah M. Ongkol N. 2016. Pengaruh Mind control training terhadap peningkatan konsentrasi pada atlet putri UKM Bola voli UNESA. Jurnal Psikologi Teori dan Praktek, Vol. 7, No. 1, 16-25, ISSN:2087-1708

Komarudin. 2015. Psikologi Olahraga. Bandung: PT. Remaja Rosdakarya.

Mylsidayu, Apta. 2014. Psikologi Olahraga. Jakarta: Bumi Aksara.

Purnama, Sapta Kunta. 2013. Latihan Imagery. JUARA (Jurnal Iptek Olahraga) Vol.1. No.1, Januari-April 2013.

Dipublikasikan Oleh :

UPT Publikasi dan Pengelolaan Jurnal

Universitas Islam Kalimantan Muhammad Arsyad Al-Banjari Banjarmasin 
Satiadarma, M.P. 2000. Dasar-dasar Psikologi Olahraga. Jakarta: Pustaka Sinar Harapan Subiyono Dkk. 2015. Afirmasi Visualisasi dan Kekuatan Pikiran. Yogyakarta: K-Media Sugara, Gian Sugiana. 2013. Terapi Self Hypnosis Seni Pemogram Ulang Pikiran Bawah Sadar. Jakarata: PT Indeks

Sukmadinata, NS. 2005. Metode Penelitian Pendidikan. Bandung PT Remaja Rosdakarya

Dipublikasikan Oleh : 